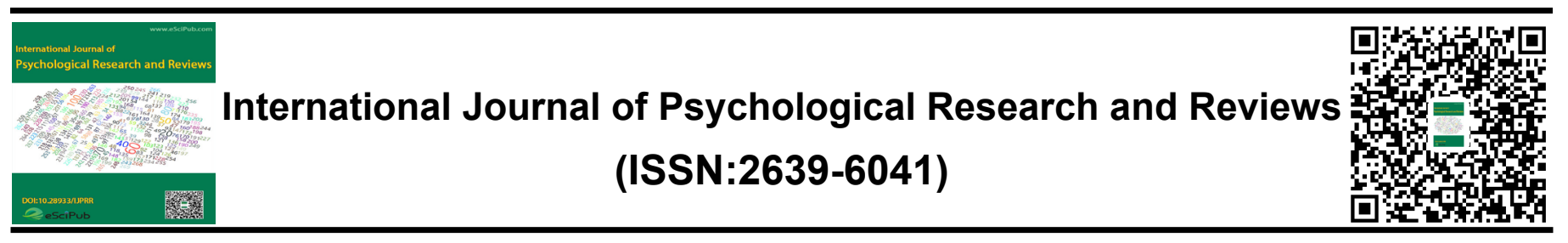

\title{
Extracurricular Types and Academic Success
}

\section{Alexis Mowrer}

Quakertown High School

\section{ABSTRACT}

Previous research has already determined that there is a positive correlation between extracurriculars and academic performance. Extracurriculars establish personal connections with others and increase motivation for many. However, there is limited research on the individual types of extracurriculars. Not all extracurriculars are the same. Therefore, I have decided to examine this issue through my research question: "Which extracurricular types were the most beneficial to academic success for 9th through 12th graders in School X in the 2020-2021 school year?" To ensure that I do not explain connections between variables, I establish an explore approach through a non-experimental survey. I ask students to list their top three extracurriculars to prevent an influx of data. After collecting my data, I organize my results into ten categories and explore recurring trends and themes. I examine mean GPA, mean class rank, personal connections with peers and adults, time spent, skills, passion, and correlating academic classes. In the end, I conclude that activities focused on leadership resulted in the highest scores overall. Student government and youth development programs may have been the most beneficial to overall academic success due to this leadership. I also determined that academic or professional organizations, the arts, and school sports may have been the most beneficial to academic success in correlating academic courses due to increased knowledge and passion. Overall, this is an essential issue to consider because over half of American students today are involved in at least one extracurricular. By establishing which extracurriculars are the most beneficial to one's success, they can better understand which activities they should be joining to make the best use of their time.
${ }^{*}$ Correspondence to Author:

Alexis Mowrer

Quakertown High School

How to cite this article:

Alexis Mowrer.Extracurricular Types and Academic Success. International Journal of Psychological Research and Reviews, 2021, 4:51.

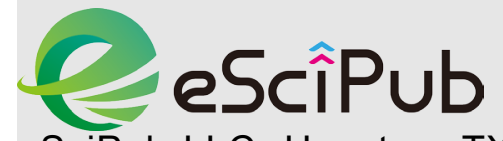
eSciPub LLC, Houston, TX USA. Website: https://escipub.com/ 


\section{Introduction}

Today, extracurriculars are popular among American students between the ages of six and seventeen (United States Census Bureau, 2014, p. 1). Well-known schools, such as Harvard and Yale, created some of the first literacy clubs in the 19th century; however, literacy clubs began to decline once athletic clubs came along. Other clubs such as journalism and newspaper arose after World War 1. At first, people considered extracurriculars an additional part of the academic schedule (Massoni, 2011, p. 2). Today, however, scholars define extracurriculars as those activities occurring outside of the classroom (Bartkus \& Nemelka, 2012, p. 1). These activities consist of student government, athletics, academic and professional organizations (aiding in job search), volunteer and service-related activities, the arts (plays, musicals, dance), honorary organizations, and much more (Rollefson \& O'Brien, 1955, p. 1). According to the United States Census Bureau, about fifty-seven percent of students today participate in at least one extracurricular. Of this fifty-seven percent, thirty-five percent of children participate in sports compared with twenty-nine percent who participate in clubs (United States Census Bureau, 2014, p. 1). Overall, extracurriculars are a significant issue to consider since many students across the United States participate in these activities after each academic school day.

\section{Previous Studies}

Sources have examined the connection between extracurriculars and academic success. According to Practical Assessment, Research, and Evaluation, a peer-reviewed journal, many researchers measure academic success through statistics such as final course grades, standardized test scores, GPAs, and class ranks (York \& Gibson, 2015, p. 1). At the University of Southern Mississippi, Lance Reed published a dissertation, which was reviewed by a group of scholars in the philosophy field. In his dissertation, he examined a study performed on select public high schools in Mississippi. He categorized his activities into athletics and nonathletics. This study found that those students who participated in extracurriculars revealed positive differences in GPA, ACT scores, and attendance rates. A limitation of this study, however, is that he did not examine the individual types of activities (Reed, 2014, p. 84). At the University of Tennessee, Anthony Watkins published a doctoral dissertation, which was reviewed extensively by a group of scholars in the education field. In his study, he organized his extracurriculars into interscholastic athletics and co-curricular activities. He found that extracurriculars resulted in a higher GPA average among these students than among fellow high school peers. Similar to the previous study, the number and types of activities students participated in were unknown (Watkins, 2004, p. 1). As can be seen in both studies, there is a definite positive correlation between academics and extracurriculars. The next question is why. Several experts have already examined why extracurricular activities contribute to higher academic standings.

\section{Grown relationships}

Many sources have found that participation in outside activities helps with social skills, improving participation and academic standing within the classroom. In the article, "Opinion: How extracurriculars benefit students' personal growth," from the University Wire, a well-known press release distribution service, Maddy Sheffield examines personal growth. She writes, "Extracurriculars provide a support system with reliable [peers] who can help students through any struggles they may face and keep them accountable" (Sheffield, 2019, p. 1). Extracurriculars remind students that they are not alone. By growing relationships with peers outside of the classroom, students have more people to seek help from about their academics. Likewise, extracurriculars also help students grow relationships with teachers. According to "Opinion: Keep extracurriculars in school," published by McClatchy-Tribune Business News, the second-largest newspaper company in 
Washington, there is an "individual engagement of teachers and students" that leads to interactive personal relationships (Alcorn, 2011, p. 1). As students learn to become more comfortable with their teachers, they are more likely to transfer these relationships to the classroom to improve their academic participation and learning.

\section{Increased Motivation}

Much of the literature has found a correlation between participation in extracurriculars and motivation. Maddy Sheffield found that extracurriculars can teach students how to manage their time better, so they do not have to sacrifice their passions. In this case, she defines a passion as an activity that one enjoys and cares a lot about (Sheffield, 2019, p. 1). Students begin realizing that the only way they can participate in activities is if their grades are sufficient, motivating them to work hard and finish tasks on time. Similarly, according to the Proquest database, another article from USA Today, an internationally distributed newspaper, explored motivation. They found that once students find activities that they are successful at, they may start to realize that their hard work pays off and may start applying this back to their schoolwork (USA Today, 2015, p. 1). Extracurriculars teach students the importance of dedication and perseverance, which are social skills that allow students to succeed in an academic setting.

\section{Hindering Academics (Limitations to Consider)}

Some sources do acknowledge that there are limitations to participating in extracurriculars. According to the Proquest database, a study conducted by the Journal of Contemporary Athletics, a peer-reviewed journal, examined 30 randomly selected collegiate non-revenue athletes. They found that 21 students believed their sport was causing more harm than good. They had limited time to complete school tasks on time. Their coaches also stressed athletic goals more than academic ones, making it harder to stay focused on them (Paule \& Gilson,
2011, p. 1). Although this study examined athletes at the collegiate level, high schoolers are still susceptible to long hours as they also participate in many extracurriculars. Certain activities require more time than others, which can be a limitation to my research. Instead of improving students' academics through grown relationships and increased motivation, it hinders academic participation due to the lack of time. Likewise, according to the BYU Undergraduate Journal of Psychology, a scholarly academic journal of the Brigham Young University psychology department, a study performed by Knifsend and Graham explored another phenomenon. They found that a high number of extracurriculars (three or more) attributed to an overload that left students with "insufficient time and energy" (Tanner, 2017, p. 6). Participation in too many extracurriculars can essentially hurt academic performance because, with limited time, students have a hard time completing school tasks and focusing on their academics.

\section{Gaps in Research}

Previous studies have discovered the positive correlation between extracurriculars and academics, the reasoning behind this, and some potential drawbacks. However, there is minimal research on the comparison between different types of extracurriculars and their academic impacts. Most studies throw all extracurriculars into one or two categories. In Reed's study, extracurriculars were organized into athletics and non-athletics to obtain data. Likewise, in the Watkins study, he organized them into interscholastic athletics and co-curricular activities. Both studies consisted of a wide range of non-athletic or co-curricular activities as well as athletic activities. This gap draws the question, "Which extracurricular types were the most beneficial to academic success for 9th through 12th graders in School X in the 20202021 school year?" The purpose of this study is to compare trends between the types of extracurriculars and high school statistics to conclude which ones might have been the most 
beneficial to academic success. Considering previous knowledge, one can assume that activities focused on improving motivation (and passion) and forming close connections with peers and teachers will enhance academic success. One can also assume that too much time spent in an extracurricular will hinder academic success. Overall, given this information, I hypothesize that those extracurriculars with close connections and those focused on improving motivation will be the most beneficial to academic success. This information will help develop a better understanding for students when they decide to pick extracurriculars. Additionally, the results provided in this paper might allow for future discussion of what schools could do to fund certain extracurriculars over others.

\section{Methodology}

In this study, I will be exploring the connections between extracurricular types and academic performance. I will be administering a survey through the Google Forms website in School X and organizing my quantitative and qualitative data into a chart. The participants in this survey include high schoolers, grades nine through twelve, in School X. Those who complete the survey will represent the general population size. The explore approach is the best approach to follow because I am looking for unknown variables. I want to identify relationships between academic success and extracurricular types. I do not know why certain extracurriculars may be more beneficial than others. Due to the Covid-19 pandemic, an online survey is also the best means of communication because all subjects have access to a school-issued laptop to take the survey. Additionally, a survey ensures anonymous results. Unlike interviews, I can obtain my data quickly and efficiently without having to examine participants one by one.

To ensure ethicality, I will make sure to follow strict protocols. I will not ask for private emails or names to maintain confidentiality. I will also inform my participants about the uses of the data. After they have finished, I will include a brief debriefing form explaining the purpose of the survey. I will also include my means of communication in case they have any questions regarding my research. Lastly, before participation, I will notify them that they are allowed to leave the survey at any time, and they may skip any questions that might make them feel uncomfortable.

I will divide my survey into two main components. The first portion will focus on academics: class ranks, GPAs, and test scores. These statistics will allow me to measure academic success and identify which extracurricular activities may have been the most beneficial. Next, I will ask the students to pick their top three extracurriculars (to prevent an influx of data), choose a category for each, and explain them. This section is essential for distinguishing between extracurriculars and identifying why certain activities may have been more beneficial than others.

As they describe their activities, I will ask them several questions. On a scale of one to five, I will have the students rate their level of enjoyment for the extracurricular. Previous studies have found that passion improves academic success, but they have not identified to what extent. This data will help me to examine the impact it could have possibly had on academic success. I will also have them rate their relationships with their peers and authority figures such as bosses and teachers. Previous studies have found that these close relationships improve academic success; however, they have not considered how beneficial these relationships are and which ones may be more worthwhile. By examining these relationships, I will better understand how extracurriculars are different from one another. I will also have them list the number of hours they spent per week on the activity. Previous research has already proved that too much time hinders academic success. However, by identifying which extracurriculars were the most time-consuming, I will better understand why some categories 
might have resulted in lower scores than others, therefore, differentiating between activities.

Additionally, in a multiple-choice section, I will include a question asking about correlating classes. Since these are knowledge-based classes, I will be looking for a connection between corresponding extracurriculars and their effects on academic performance. I will be asking for their grades in these classes. Hence, I can identify if there was a rise in academic success due to an individual course. Overall, this new knowledge is essential for the overall purpose of my survey because it explores how certain extracurriculars might have benefited academic scores in different ways. Lastly, in a free response question, I will have the students list specific skills that they learned within the extracurricular. Previous studies have found that skills are beneficial to one's academic success. However, they have not determined which ones are the most favorable, which is why this is a good question to consider when reviewing my results.

Some limitations will result from my research. First of all, I will have trouble reaching some virtual students, which could essentially skew the data and limit the group towards in-school participants. Students may also misinterpret the questions because I cannot stand in front of a classroom and administer the survey to the students. Additionally, students may feel rushed to finish the questionnaire quickly due to the environment. Lastly, students may choose to skip questions due to voluntary participation. Some questions require specific knowledge for statistics like GPA and class rank. However, a student might not know these statistics on the top of their head. Consequently, this could skew the results because I might not have adequate data if sections are continuously left blank.

After collecting all my data, I will be categorizing the results using a chart. I will first calculate the average class rank, GPA, and test scores for each category. Then, I will calculate the average time these students spent, the top skills that the students learned, and the close connections each student made within each category. Ultimately, this method aligns with my overall research question. By comparing statistics such as class ranks to other factors such as time, level of enjoyment, and skills, I will better understand what distinguishes one extracurricular type from another. Consequently, I will have the ability to identify which extracurricular activities might have been the most beneficial to academic success based on these certain factors.

\section{Results}

In my research survey, I obtained 180 responses overall, enough data to represent the general population size. As the results came in, I realized that many students in the 2020 and 2021 school year did not have an SAT or ACT score because they could not take them due to Covid. I decided to remove these scores from my data because it would present some bias in the limited sample size. Next, as I began to categorize the activities, I realized that some categories were more common among students than others. In the end, I discovered that there were about ten categories of extracurriculars, which included academic organizations, student government, school sports, multicultural activities, the arts, honorary organizations, religious organizations, part-time jobs, youth development programs, and club sports. I also added an extra column labeled "none" to act as a control group.

As displayed in Figure 1, those who participated in no extracurriculars had an average mean GPA of 3.12. All other activities achieved higher GPA scores. Most extracurriculars received scores between the 3.5 and 4.0 range. Those in student government reported having the highest GPA scores, with an average of 4.08. In contrast, those in school sports reported the lowest GPA scores, with an average of 3.43. As portrayed in the results, there was no distinct difference between GPA scores and the extracurricular type, except for those in school sports.

Next, I examined connections between the extracurricular type and mean class rank. I utilized percentiles to measure the percent of 
cases that were at or below a score. In this case, organizations, school sports, and the arts the closer a student is to a class rank of 1 , the resulted in the lowest mean class rank higher their mean class rank percentile. As percentiles of 86.9, 81.2, and 87. Compared illustrated in Figure 2, student government and with school sports, club sports were higher by youth development programs had the highest 7.9. Unlike in my GPA section, I chose not to class rank percentiles of 99.5 and 94.5. add an extra column for "none" because many Multicultural activities, honorary organizations, students, who I asked, left this section blank. and religious organizations closely followed, Therefore, I did not obtain enough adequate each with a percentile over 90 . Academic data.

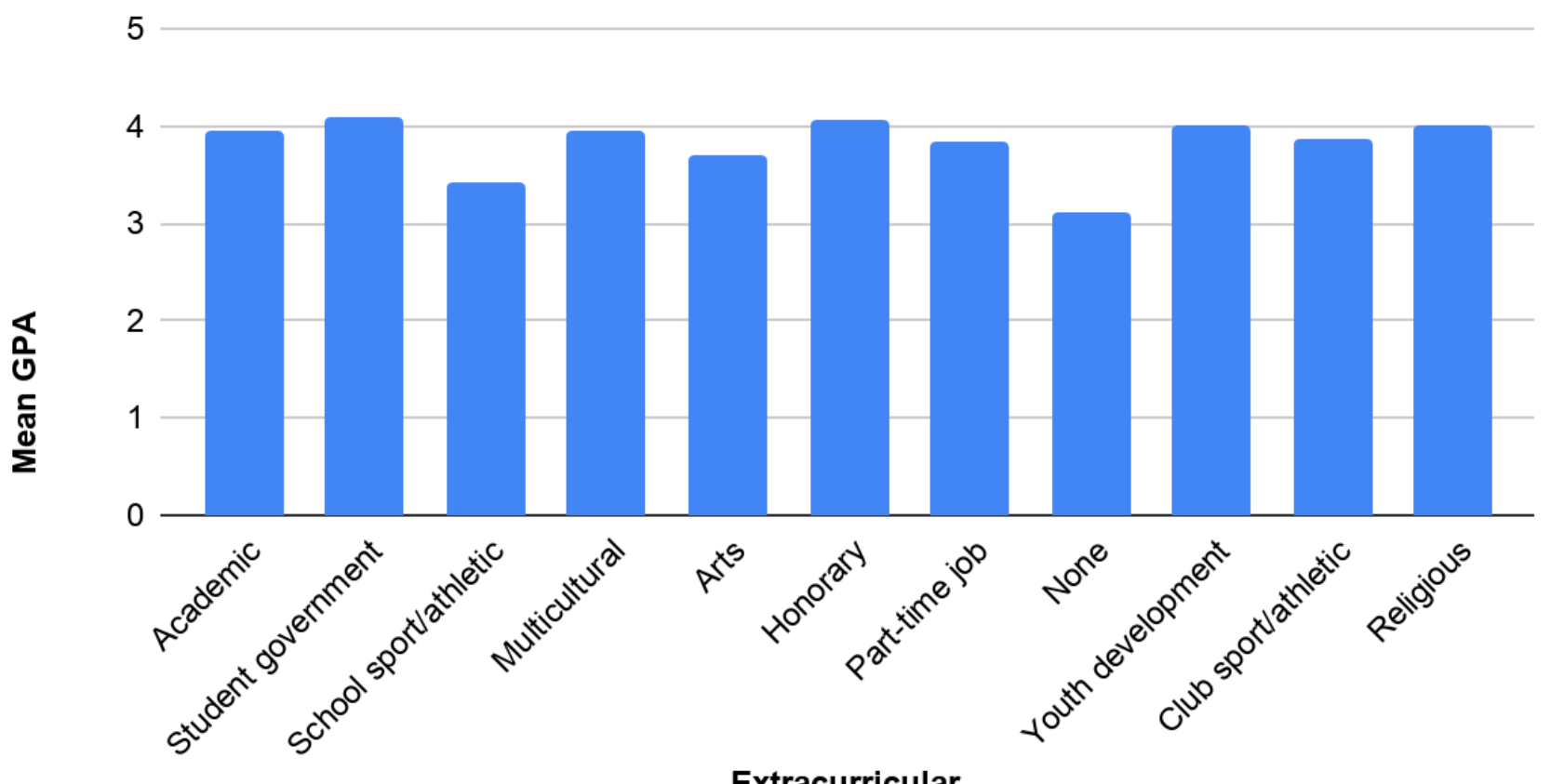

Figure 1. Examining student mean GPAs in different types of extracurriculars

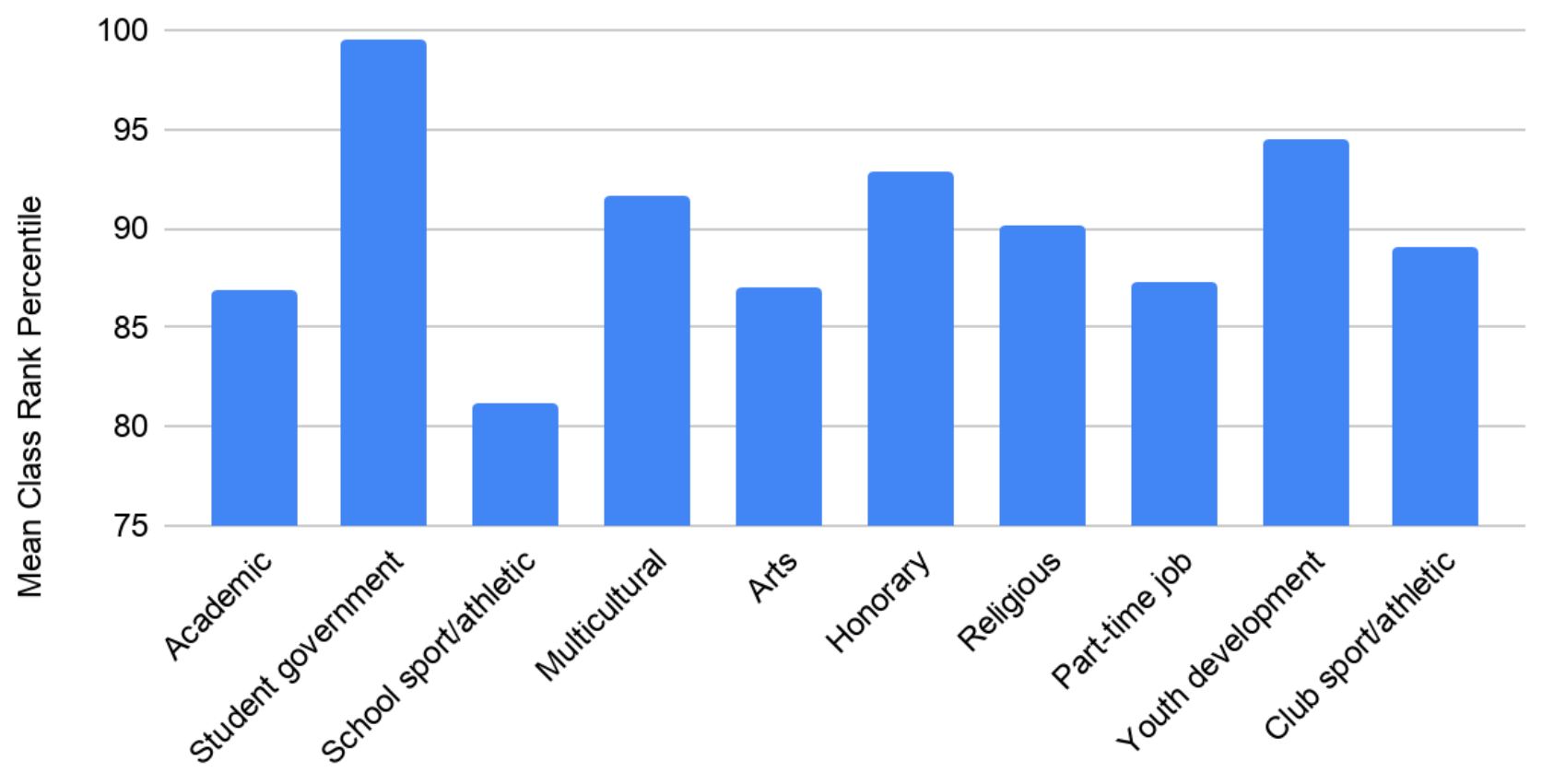

Type of Extracurricular

Figure 2. Measuring Mean Class Rank Percentiles for each type of extracurricular 


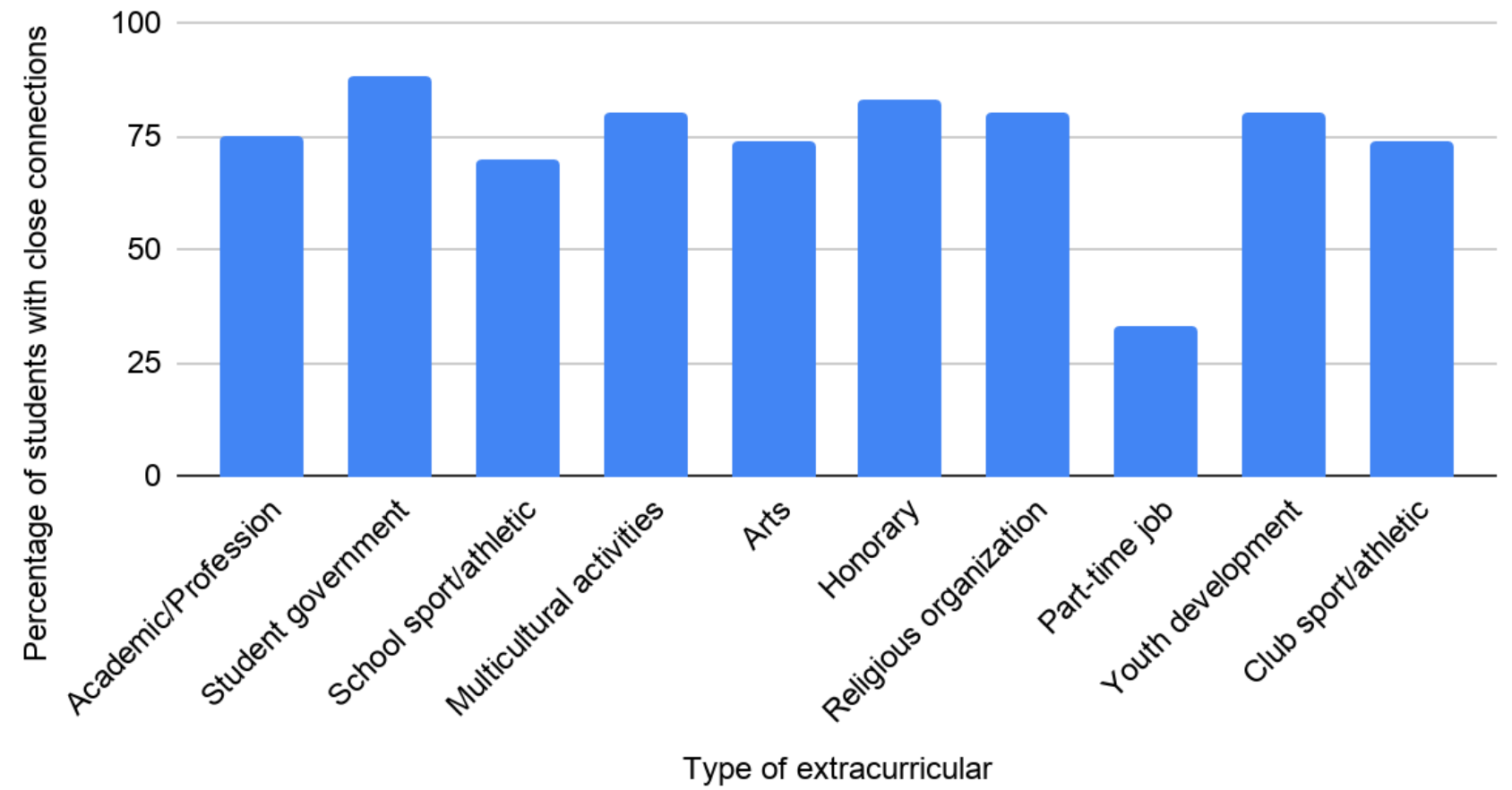

Figure 3. Measuring close, meaningful connections with their peers within specific extracurriculars

I then decided to examine the personal connections students made with their peers and adult advisors or coaches. As reported in Figure 3 , I found that most of the activities resulted in close and meaningful connections with their peers. Student government with an $88 \%$ and youth development programs with an $80 \%$ had the highest percentages. Multicultural activities, honorary organizations, and religious organizations closely followed, each with a score over $75 \%$. In contrast, the one main outlier, in this case, was with part-time jobs. About twothirds of students with part-time jobs reported having distant relationships with their coworkers and peers.

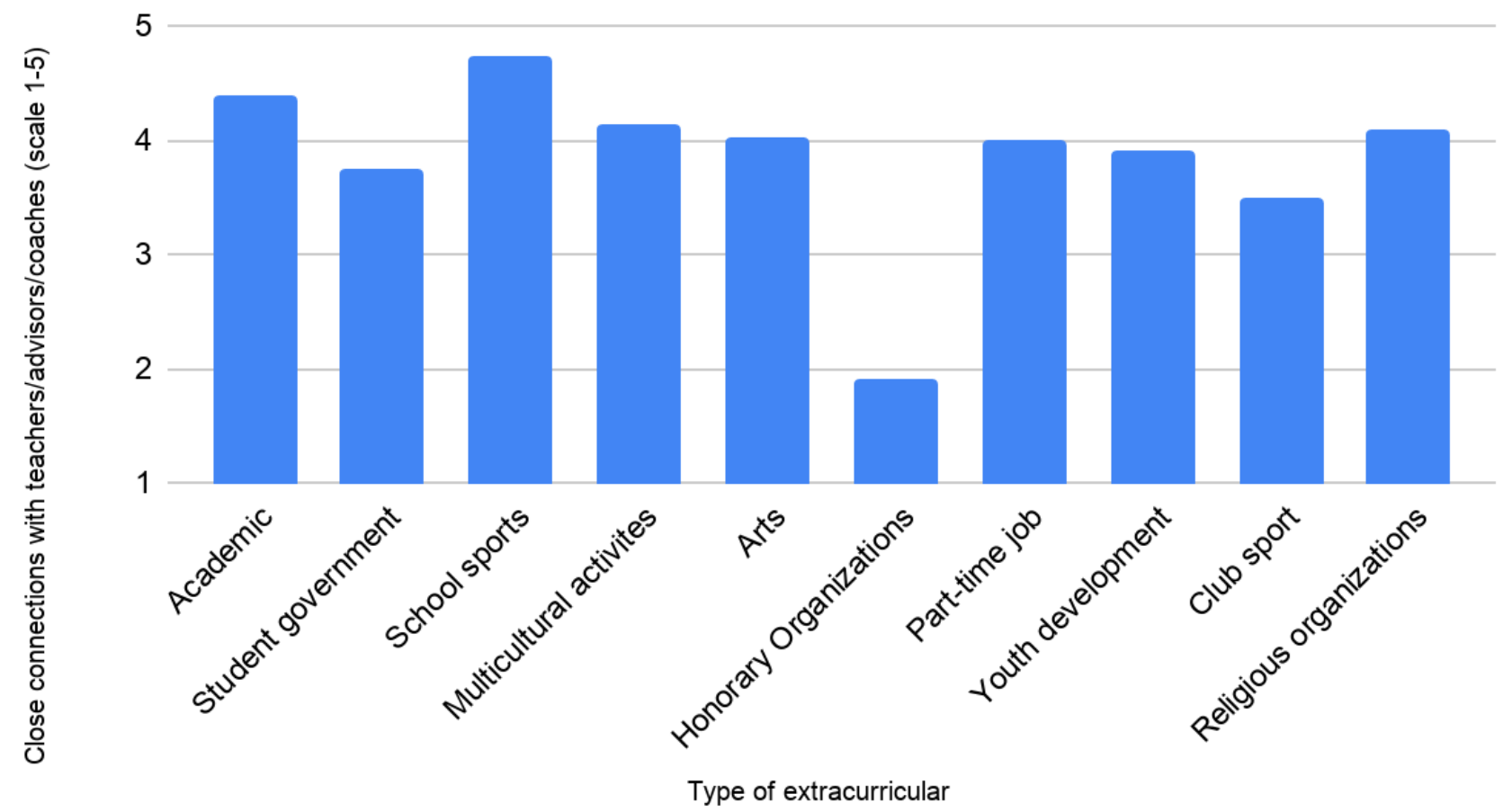

Figure 4. Examining close connections with teachers/advisors/coaches (scale 1-5) within activities 


\section{Club sport}

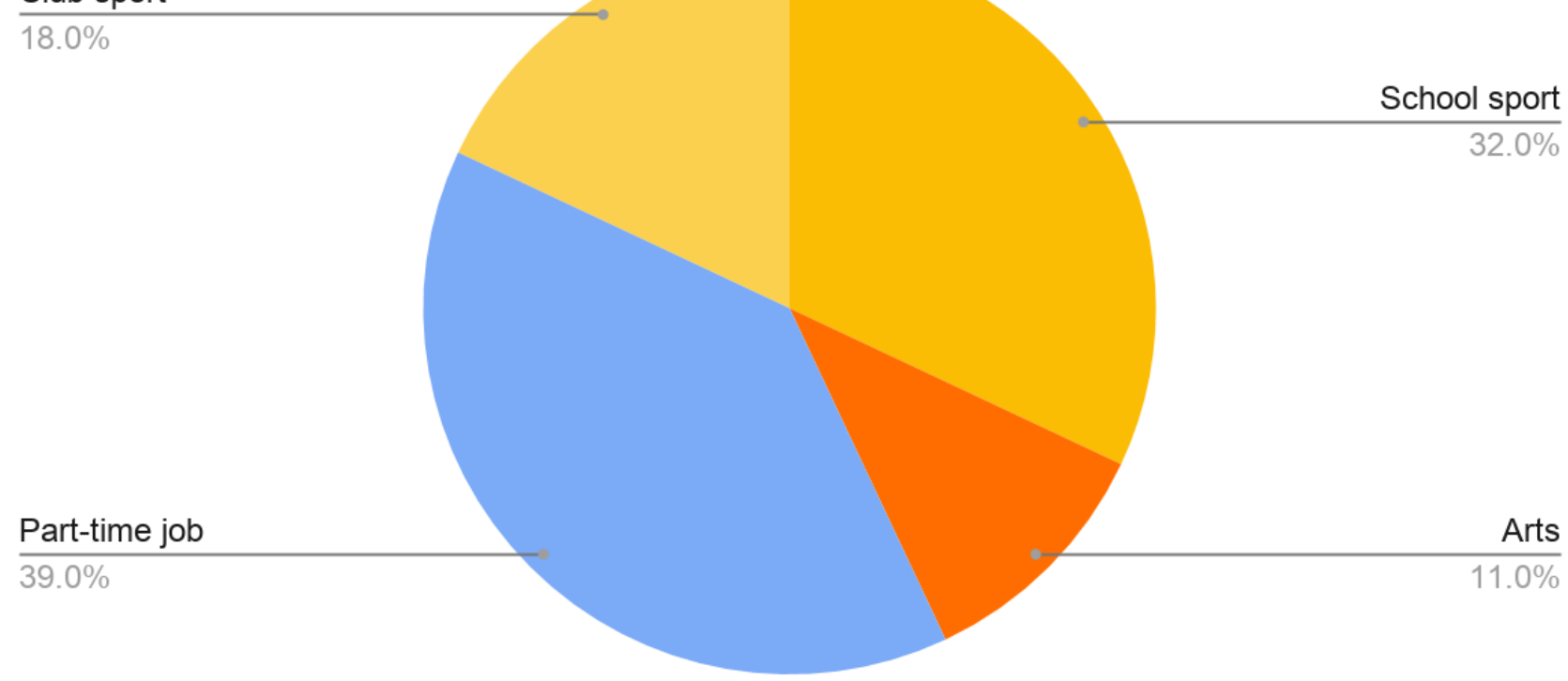

Figure 5. Students who spend more than 8 hours on their activity

\begin{tabular}{|l|l|}
\hline \multicolumn{2}{|l|}{ Table 1. Examining top skills that are learned within extracurriculars } \\
\hline Type of extracurricular & Top skill(s) learned \\
\hline Academic Organization & Knowledge \\
\hline Student government & Leadership \\
\hline School sport & Knowledge \\
\hline Multicultural activity & Communication \\
\hline Arts & Knowledge \\
\hline Honorary organization & Communication \\
\hline Religious organization & Communication \\
\hline Part-time job & Communication \\
\hline Youth development (resolving societal issues) & Leadership \\
\hline Club sport & Dedication \\
\hline
\end{tabular}

In Figure 4, I found that the academic organizations, school sports, multicultural activities, the arts, and religious organizations all had strong relationships with their adult advisors and coaches, with the average score being above a 4 out of 5 . Additionally, those students in part-time jobs also reported an average score of 4 , while all other activities followed with an average score between 3 and 4 . In contrast, the one main outlier, in this case, was honorary 
organizations. They reported an average score of 1.9 .

Next, I looked at the average time students spent within each extracurricular. Those in school sports and part-time jobs reported spending the most time in their activities. In Figure 5, 39\% of students in part-time jobs and $32 \%$ of students in school sports spent more than eight hours per week on their activity. Only $18 \%$ of students in club sports reported spending more than eight hours per week. Compared with school sports, this is a $14 \%$ difference.

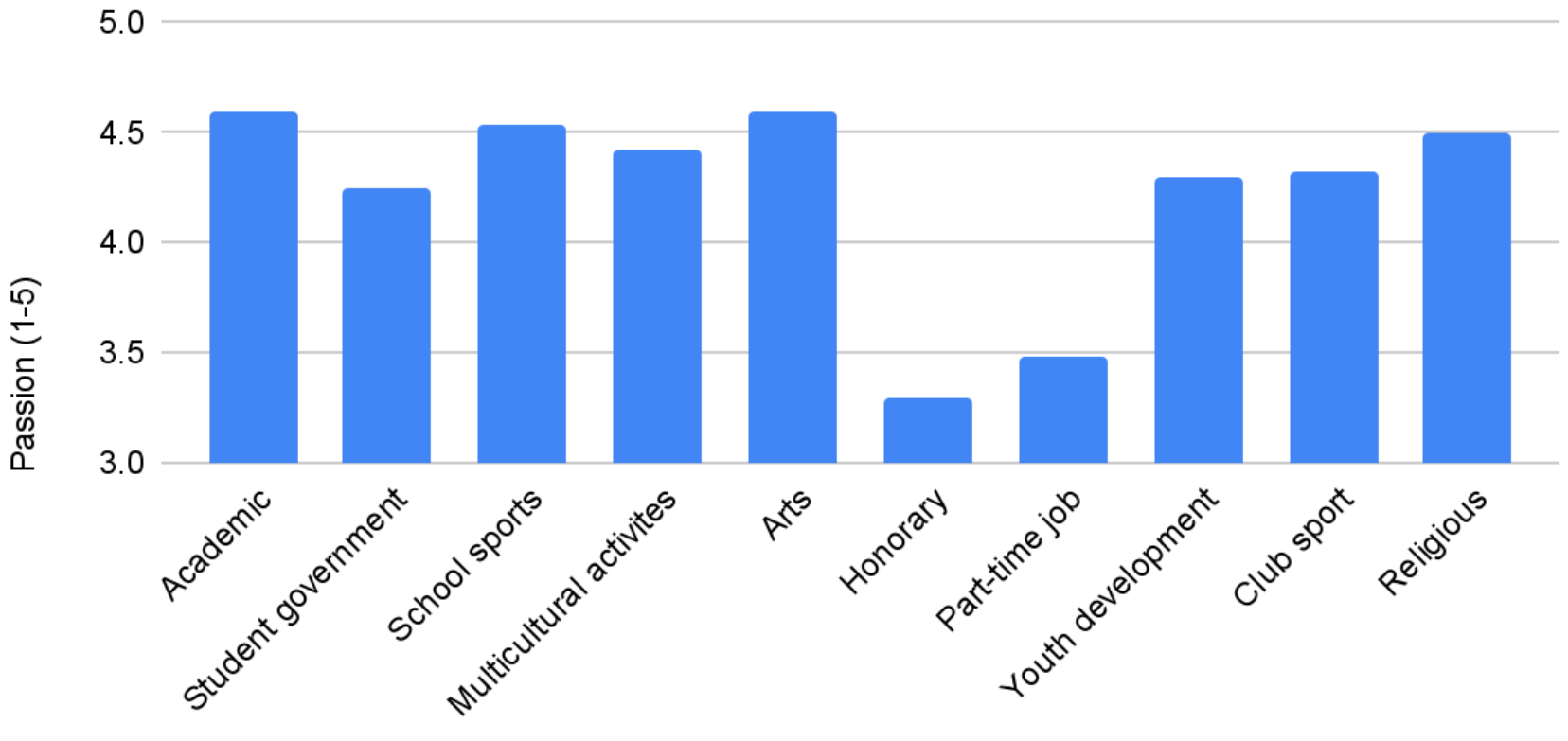

Type of extracurricular

Figure 6. Measuring how passionate students felt about their activity on a scale 1-5

As I ranked student enjoyment, I found that students were more passionate about certain activities than others. In Figure 6, students reported being more passionate about academic organizations, school sports, and the arts. On a scale of one to five, each of them scored above a 4.5. The two main outliers were honorary organizations and part-time jobs. Honorary organizations scored the lowest with a score of 3.3. Part-time jobs closely followed with a score of 3.48 .

As I collected my data for the free-response question, I started noticing recurring themes. Knowledge, leadership, communication, and dedication were the most common themes I observed. I then found the top skill within each extracurricular by taking the highest percentage of students who had reported learning that specific skill. As shown in Table 1, student government and youth development programs displayed leadership. Multicultural activities, religious organizations, honorary organizations, and part-time jobs were geared more towards communication. Those in club sports focused on improving motivation as well as dedication. Additionally, students in academic organizations, the arts, and school sports reported knowledge as their top skill.

Lastly, as I examined the grades of correlating classes, I had begun to see a trend. Although some did not show high scores overall, some had shown higher scores within individual courses. The majority of students in academic organizations, school sports, and the arts reported participation in correlating classes during their school year. I asked these students if they usually did better in these classes compared to their other courses, and I had them rate their grades on a scale of one to five. In Figure 7, academic organizations reported a mean score of 4.3 , and school sports and the arts reported a mean score of 4.6. 
5

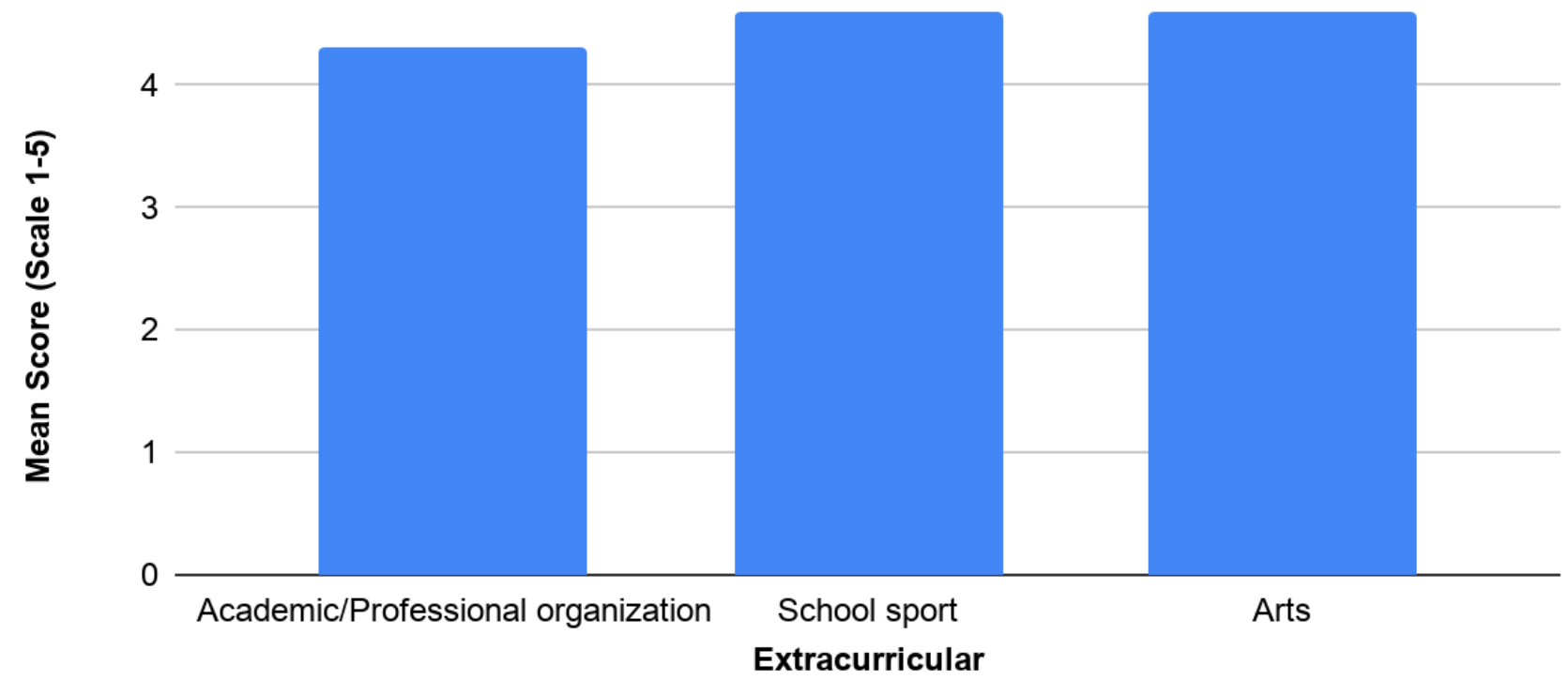

Figure 7 . Identifying extracurriculars and measuring performance in correlating academic classes from a scale 1-5

\section{Discussion}

This data already proves previous research studies about the positive correlation between extracurriculars and academic achievement. I found the control group resulted in a mean score far below the average of the extracurricular scores. However, the one outlier I found was with school sports. It was not much higher than the control group. To determine why this might have been the case, I compared its mean score with club sports, which are both significantly similar activities. I found that club sports had a much higher GPA. Looking at Figure 5, most students reported spending more time in school sports than in club sports. Considering this data agrees with what previous studies have found about too much time hindering academics, one might assume that these students may have lost motivation to complete tasks, which is why their GPA scores fell. In fact, when I created Table 1, I found that dedication was more common among club sports than school sports. Consequently, this may have also resulted in higher class rank percentiles for those students because they had the time and energy to put in more effort and even take more challenging classes, agreeing with what previous studies have said about motivation and academic success.

Noticing that there were no significant gaps between GPAs and extracurricular type, I had begun to analyze the differences in class ranks. I first examined the extracurriculars with the lowest class rank percentiles, including academic organizations, school sports, and the arts. As shown in Table 1, all three of these activities reported knowledge as their highest skill. I had a hard time understanding why they resulted in low scores considering knowledge is an essential aspect for academic success. However, I did notice a trend. All three of these extracurriculars had students taking correlating classes within school, and students reported doing significantly better in these classes than in their other courses. From these trends, I determined students in knowledge-based extracurriculars may do better in classes where they end up using this knowledge. Overall, this new knowledge adds to previous studies and fills in my gap by addressing the differences between individual scores rather than overall scores.

I also noticed that these students in the knowledge-based classes were more passionate about their activities, as illustrated in IJPRR:https://escipub.com/international-journal-of-psychological-research-and-reviews/ 10 
Figure 6. Previous studies have said that passion leads to more motivation, which, in this case, I found to be partially correct. These students received higher grades within their correlating classes, which might have been due to increased motivation. However, it did not increase motivation throughout all of their classes because, if it did, my results would have probably shown higher GPAs and class ranks. Overall, this new information adds to what existing research has said about the impact of passion. I found that being passionate may be more beneficial for improving individual scores rather than overall scores.

Next, I compared religious organizations, multicultural activities, honorary organizations, and part-time jobs because each one of these activities focused on communication. I found that the first three extracurriculars were close in class rank scores; however, part-time jobs were not. Looking at Figure 3, I noticed that part-time jobs had a significantly lower percentage of close peer connections than the rest of the extracurriculars. On the other hand, in Figure 4, I noticed that part-time jobs had a much higher score, much closer to the average, with their bosses. These activities focus on establishing formal relationships with those higher up than them. Since they interact with people with differing values and beliefs, they must learn how to adapt, developing their communication skills. In contrast, students in religious organizations, multicultural activities, and honorary organizations are around peers with similar values and interests, so they are much more likely to create closer connections that last longer. These closer connections may have been what resulted in higher class rank scores, illustrating that they may be more beneficial to academic success. Overall, this data agrees with what previous studies have said about having relationships and academic success, but it also adds to this knowledge. My results have shown that extracurriculars with close peer connections may be more significant than those connections with authority figures.
This information has led me into my last two extracurriculars, student government and youth development (societal issue) programs, each with the two highest class rank percentiles. In addition to this, both of them had leadership as the top-most skill. As I examined Figures 3 and 4 , I saw that both clubs had closer connections with their peers than their teachers. Considering what I concluded in my previous paragraph, these connections may have been more significant for their academic success. However, they went a step further to lead their peers, most likely enhancing their communication skills even further. Overall, I concluded that those extracurriculars whose focus is leadership might be more significant for academic success than those whose focus is around simple connections with their peers. This new knowledge expands on previous studies and fills in that gap by identifying which skills may be the most beneficial to one's academic scores.

\section{Conclusion}

Previous studies have already examined that extracurriculars, as a whole, improve academic success and that there are specific qualities that contribute to this success. However, there is limited research on which activities consist of students with the highest academic success considering the skills these students possess, which draws my research question: "Which extracurricular types were most beneficial to academic success for 9 th through 12th graders in School X in the 2020-2021 school year?" After analyzing all of my results, I have concluded that my hypothesis was incorrect. Although activities focused around motivation and communication resulted in higher scores than the control group, I found that activities focused on leadership resulted in the highest scores overall. Student government and youth development programs may have been the most beneficial to overall academic success due to this leadership. I also determined that academic or professional organizations, the arts, and school sports may have been the most beneficial to academic success in correlating academic courses due to 
increased knowledge and passion. In answering this question, it is essential to acknowledge what a person is referring to when saying highest academic success. There is a difference between overall academic achievement and individual class achievement. Once one considers this particular aspect, they can use this information in helping them decide which extracurriculars might be the most beneficial to their academic career. However, they must keep in mind that this is not guaranteed to happen because I did not examine a cause-andeffect relationship.

\section{Limitations}

In my study, it is crucial to consider many limitations that could have affected my results. Firstly, due to the Covid pandemic, I could not compare standardized test scores such as SAT or ACT. Consequently, I was only able to analyze the relationship between extracurricular types and their influence on high school grades. SAT and ACT scores generally measure a student's readiness for college. By measuring standardized test scores, this would have been a different measure for academic success. I would not only be examining high school success but also future academic success. Additionally, some students could have possibly had the grades and statistics going into the extracurricular activity. Leadership programs such as student government and honorary organizations such as the National Honors Society often require that students possess the skills and knowledge before joining the extracurricular. Many times students have to earn their positions in a club. Therefore, in my results, I cannot say that an activity impacted academic success due to confounding variables. Rather than examining a cause-and-effect relationship, I was only observing for unknown variables. Furthermore, one must keep in mind that not all clubs within a fixed category are the same. There might be something about a specific club that sets it apart from other clubs within that category, skewing the results. For example, the Future Business Leaders of
America Club (FBLA) and the Environmental Club are both considered academic-learning clubs. However, FBLA focuses on building those professional and business-related skills, while the Environmental Club focuses on preserving the natural environment. Although both clubs teach the essential knowledge needed for a specific field, they are two separate clubs with many differences. Since FBLA is more common in School $X$, the results from these students may have represented the majority of the category, therefore, skewing my results. Lastly, many activities could have fallen under more than one category. For example, many might acknowledge the marching band as an academic organization, in addition to an art club, because students are learning the essential knowledge needed within a specific field. Consequently, I had to make an educated guess about where to place certain activities. However, other researchers might choose to separate the same extracurriculars into different categories in future studies, therefore, producing different results.

\section{Future Research}

Future researchers should consider conducting more research to address these limitations in my study. Considering I did not implement an experiment, I suggest studying the issue for causation to ensure which extracurriculars are the most beneficial and for what reasons by removing any confounding variables. Additionally, I suggest that they examine activities one by one or develop a standard list of categories. Therefore, this eliminates any confusion about what belongs to what category and how they contribute to improving one's academic success. Lastly, I consider that future studies look into extracurricular types and their influence on standardized test scores. This knowledge would allow for a more well-rounded discussion, focusing on the present and future academic success.

\section{Implications}

Overall, extracurriculars have such a significant $\begin{array}{lr}\text { impact on students because almost fifty-seven } \\ \text { urnal-of-psychological-research-and-reviews/ } & 12\end{array}$ 
percent of students participate in at least one extracurricular activity today, which is why exploring the real-world implications for this community can be influential. My results suggest that those extracurriculars which focus on the same skills will result in similar academic scores. From my data, I learned that activities associated with leadership tended to result in higher academic scores overall. However, those focused on knowledge and passion resulted in the lowest GPAs and class ranks but higher individual course grades. Having this knowledge is essential for students when it comes time to choosing an extracurricular activity. By knowing distinct differences between types of extracurriculars and what skills each extracurricular focuses on, students can make the best use out of their time. If they want to improve their scores within a specific class, I suggest they look into activities focused on knowledge and passion. If they have a hard time in general, I recommend finding activities that focus on developing one's leadership or communication skills. They must explore their options and decide what they want out of an extracurricular before diving into any specific one. My results also imply that schools can use this information while funding their programs. Many times they only have a limited amount of space and money for extracurriculars. This knowledge allows for future discussion of what schools could do to fund particular activities over others to receive the best academic results. Extracurriculars may be beneficial as a whole, but the specified type establishes to what extent they are beneficial.

\section{References}

[1]. Alcorn, W. (2011). Opinion: Keep extracurriculars in school. McClatchy - Tribune Business News. Retrieved from https://search.proquest.com/docview/88753266 8 ? accountid $=41066$

[2]. Bartkus, K. R., \& Nemelka, B. (2012). Clarifying the meaning of extracurricular activity: A literature review of definitions. American Journal of Business Education (AJBE), 5(6), 693-704. Retrieved

from https://www.proquest.com/docview/141844771
$6 ?$ pq - origsite $=$ gscholar

[3]. Massoni, E. (2011). Positive effects of extracurricular activities on students. Retrieved from

https://dc.cod.edu/cgi/viewcontent.cgi?article $=1$ $370 \&$ context $=$ essai

[4]. Paule, A. L., \& Gilson, T. A. (2011). Does athletic participation benefit or hinder academic performance? Non-revenue sport athlete experiences. Journal of Contemporary Athletics, 5(3), 203-217. Retrieved from https://search.proquest.com/docview/ 1732935091 ? accountid $=41066$

[5]. Reed, L. (2014). Relationships between participation in extracurricular activities, ACT scores, GPA, and attendance in select public high schools in Mississippi. Retrieved from https://aquila.usm.edu/dissertations/368/

[6]. Rollefson, M., \& O'Brien, E. (1995). Extracurricular participation and student engagement. National Center for Education Statistics. Published. Retrieved from https://nces.ed.gov/pubs95/web/95741.asp

[7]. Sheffield, M. (2019). Opinion: How extracurriculars benefit students' personal growth. University Wire. Retrieved from https://search.proquest.com/docview/22846377 1 2? accountid $=41066$

[8]. Student grades rise with extracurriculars. (2015). USA Today. Retrieved from https://search.proquest.com /docview $/ 1752515929$ ?accountid=41066

[9]. Tanner, B. (2017). Effects of extracurricular activities and physical activity on academic success. BYU Undergraduate Journal of Psychology. Retrieved from https://scholarsarchive.byu.edu/cgi/viewcontent .cgi?article $=1171 \&$ context=intuition

[10]. United States Census Bureau. (2014). Nearly 6 out of 10 children participate in extracurricular activities. Retrieved from https://www.census.gov/news room/pressreleases /2014/cb14-224.html

[11]. Watkins, A. B. (2004). The effects of participation in extracurricular activities on the mean grade point average of high school students in a rural setting. Retrieved from https://trace.tennessee.edu/utk_graddiss/4580/

[12]. York, T., \& Gibson, C. (2015). Defining and measuring academic success. Practical Assessment, Research, and Evaluation. Retrieved from https://scholarworks.umass.edu/pare/ vol20/iss $1 / 5 /$ ?utm_source=scholarworks.umass .edu\%2Fpare\%2Fvol20\%2Fiss 1\%2F5\&utm_m edium=PDF\&utm_campaign=PDFCoverPages 